\title{
Fenomenología de la donación, hermenéutica y religión en la obra de Jean-Luc Marion
}

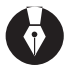

Jorge Luis Roggero

Universidad de Buenos Aires- Consejo Nacional de Investigaciones Científicas y Técnicas, Argentina.

Dirección: tesis en co-tutela. Por la Universidad de Buenos Aires: Prof. Dr. Roberto Walton; por la Universidad de Paris IV-Sorbona: Prof. Dr. Dominique Pradelle.

Jurado: Prof. Dr. Xavier Bassas Vila (Universidad de Barcelona), Profa. Dra. Carla Canullo (Universidad de Macerata), Prof. Dr. Éric Stéphane Pommier (Universidad Católica de Chile) y Prof. Dr. Luis Román Rabanaque (Universidad Católica Argentina).

Fecha de defensa: 19 de junio de 2018.

Asistimos, en este segundo decenio de los años dos mil y desde hace ya varias décadas, a un "momento francés de la fenomenología", y la obra de Jean-Luc Marion es, ciertamente, la más emblemática de este "momento". La tesis se propuso un análisis de los límites y posibilidades de la fenomenología marioniana y, a través de ella, en buena medida, también de la nouvelle phénoménologie.

El método para emprender la investigación fue doble. Por un lado se planteó un paralelo heurístico con la fenomenología del joven Heidegger. Por otro lado se siguió el hilo conductor de la objeción como el motor que permite extraer la expresión más propia de la fenomenología de la donación. El proyecto marioniano recibió dos grandes objeciones desde sus comienzos: 1) la objeción hermenéutica y 2) la objeción teológica. 1) La primera crítica fue formulada desde la publicación de Réduction et donation, y refiere a la necesidad de aclarar si existe alguna función de la hermenéutica en la fenomenología de la donación. Autores como Jean Greisch, Jean Grondin, y más recientemente, Shane MacKinlay, Claudia Serbany Christina Gschwandtner consideran necesaria una explicitación del modo en que la fenomenología marioniana puede articularse con una hermenéutica. Marion fue receptivo a esta demanda y ofreció una primera respuesta en el capítulo II de su libro de 2016, Reprise du donné, asignando a la hermenéutica la tarea de gestionar el pasaje entre lo que se da y lo que se muestra.

2) La segunda crítica se remonta al célebre texto de Dominique Janicaud, Le tournant théologique de la phénoménologie française, de 1991, y fue retomada por Jocelyn Benoist, François Laruelle y Marie-Andrée Ricard. En líneas generales, estos autores afirman que no existe una distinción disciplinaria clara entre teología y fenomenología en la obra de Marion y, por lo tanto, su trabajo fenomenológico carece de validez o, al menos, de rigor metodológico. Marion también ha ofrecido una respuesta a esta objeción en diversos pasajes de su obra. Baste aquí con recordar la distinción, introducida en Étant donné, respecto del estatuto del fenómeno de la revelación evaluado en tanto posibilidad desde la fenomenología y en tanto efectividad desde la teología.

La objeción cumple un rol decisivo en la obra marioniana, que permite desplegar sus posibilidades latentes. Étant donné -su obra principal, en la que se expone sistemáticamente la idea de una fenomenología de la donación- encuentra una motivación profunda en la necesidad de responder a las cuestiones que sus críticos le habían planteado respecto de Réduction et donation. Y lo mismo puede decirse de sus textos fenomenológicos subsiguientes, hasta su último libro, Reprise du donné, en el que el propio autor reconoce que la totalidad de la obra se estructura como respuesta a diversas objeciones. De más está decir que este gesto no es nuevo en filosofía, Marion no hace más que seguir los pasos de su maestro Descartes, pero en su caso, la interacción con otros pensadores tiene, en buena medida, un carácter estructurante para su propia obra.

La hipótesis de la tesis consistió en sostener que por medio de una indagación en la objeción hermenéutica y en la objeción teológica es posible advertir cómo ellas conducen a desplegar la posibilidad última y más propia de la fenomenología de la donación: la de una hermenéutica del amor.

Рara alcanzar este objetivo, en la primera parte de la tesis se analizó en detalle cada uno de los cuatro elementos que componen la fenomenología marioniana: el concepto de fenómeno, la noción de donación, la reformulación de la reducción y la subjetividad receptiva del adonado. Los cuatro componentes responden a una matriz heideggeriana radicalizada.

Una vez establecido el funcionamiento básico de la fenomenología de la donación, en la segunda parte, abordé las dos objeciones. Si el fenómeno ya no es un "fenómeno llano", es decir, ya no se deja reducir a mera 
presencia para una conciencia, sino que surge a partir de su propia iniciativa y si, además, su darse tiene un carácter enigmático, pues se encuentra atravesado por capas interpretativas que ocultan su verdadero sentido, entonces, con buen tino, Heidegger advierte que es necesario imprimir un "giro hermenéutico" a la fenomenología. Marion acepta plenamente esta consecuencia que extrae Heidegger de la definición del fenómeno y aunque en sus primeras obras fenomenológicas no lo hace de modo explícito, como bien señala Jean Greisch, pueden encontrarse en ellas categorías que operan poniendo en práctica una hermenéutica (ej. anamorfosis). Asimismo, la "puesta en marcha" (hermeneutische Einsatz) de la hermenéutica marioniana -como la del joven Heidegger- también está dada por una experiencia fundamental. Este aspecto es expuesto por Marion en su obra sobre Courbet. Allí el fenomenólogo francés propone la disposición afectiva de la "pena"-una modalidad del amor-como el motor de una hermenéutica estética que permite el pasaje de lo invisto a lo visto, i. e., de lo que se da a lo que se muestra. Sin embargo, cabe reparar en cierta diferencia respecto de la propuesta heideggeriana: la hermenéutica marioniana es también una hermenéutica del acontecimiento, es también una hermenéutica de lo que excede toda estructura de anticipación y toda inscripción en un mundo. Es necesario, pues, encontrar un tipo de hermenéutica que sea capaz de operar con una racionalidad que exceda la racionalidad metafísica de los objetos intramundanos.

Esto nos lleva a la segunda objeción: la objeción teológica. Marion -también como el joven Heidegger-entiende que la filosofía puede ser revitalizada si reanuda su diálogo con la teología. Los fenómenos saturados -que nos salen al encuentro en nuestra cotidianidad y que constituyen los "fenómenos decisivos" para darle sentido a nuestra existencia- demandan una ampliación de la racionalidad. Esta tarea exige una revisión de la "secularización", una revisión del modo en que la modernidad reduce la concepción de la racionalidad a la razón científica y excluye todo lo que no responde a estos cánones como irracional o perteneciente al campo de la creencia o de la fe. Marion desarticula la oposición entre fe y razón, y acude a la teología en búsqueda de ideas que permitan ampliar la racionalidad filosófica. En este sentido, Marion sigue la estrategia heideggeriana de apropiación filosófica de ideas teológicas. Muchas categorías de la fenomenología de la donación reconocen una inspiración teológica. Sin embargo, esto no anula su valor filosófico, pues operan en la inmanencia del ámbito fenomenológico demostrando su fecundidad.

Una de estas categorías es la del amor. Con esta noción, es posible responder a la necesidad de una hermenéutica que opere desde otra racionalidad. El amor impone su propia lógica. Desde el temple anímico del amor es posible transformar la mirada y la racionalidad para ser capaces de recibir y fenomenalizar, en sus propios términos aconteciales, a los fenómenos paradójicos que determinan nuestra existencia. Como bien señala Emmanuel Housset, el amor en Marion es principalmente un "poder de fenomenalización".

De este modo, la hermenéutica del amor ofrece la respuesta a las dos objeciones fundamentales recibidas por la fenomenología de la donación y expresa una de sus posibilidades más extremas, pues sus consecuencias se registran en el dominio teórico, pero también y fundamentalmente, en el práctico. 